\title{
Operación massmediática: re-elaboración de la memoria pública y conformación del archivo contemporáneo*
}

\author{
Marcelino García**
}

\section{Resumen}

En este ensayo delineamos algunas ideas y articulamos reflexiones desarrollas por nosotros a lo largo de los últimos años sobre una de las cuestiones de interés en el campo de estudios humanos y sociales: memoria/massmedia. La mass-mediación es central en el complejo proceso mnemosemiótico y comunicativo que es la cultura y en la intrincada conformación del archivo del mundo contemporáneo. La operación massmediática es cada vez más importante en el conflictivo trabajo y los días de la memoria pública, con poco que se observe la reconfiguración de los distintos escenarios locales, regionales, nacionales, mundiales y globales que realiza la sinergia de medios-industrias culturales-turismo y otros "órganos" del complejo socio-cultural. La constelación semiótico-discursiva 'memoria-historia' es uno de los asuntos importantes de la agenda mediática, que diariamente despliega la acción y fuerza de los signos para re-actualizar los sentidos del presente, reelaborar el pasado y reconfigurar el futuro.

\section{Palabras clave}

Operación massmediática - memoria - archivo.

\footnotetext{
* Artículo recibido el 10 de marzo de 2013. Aceptado el 10 de octubre de 2013.

**Dr. en Ciencias de la Información por la Universidad de Barcelona, Docente e investigador UNaM.
} 


\begin{abstract}
In this essay we outline some ideas and articulate reflections develop for us throughout the years on one of the issues of concern in the field of human and social studies: memory / mass media. The mass-mediation is central to the complex process that is mnemosemiótico and communicative culture and the intricate file conformation of the contemporary world. The mass-media operation is increasingly important in the troubled days of work and public memory, is observed with little reconfiguration of the various local, regional, national, global and performs global media synergy-industries cultural-tourism and other "organs" of the complex socio-cultural. The semiotic constellation-discursive 'memory-history' is one of the important issues of the media agenda, which displays daily action and force the signs to re-update the senses of this, rewrite the past and reshape the future.
\end{abstract}

\title{
Keywords
}

Operation massmediatic - memory - archive.

"De tiempo somos.

Somos sus pies y sus bocas. Los pies del tiempo caminan en nuestros pies.

A la corta o a la larga, ya se sabe, los vientos del tiempo borrarán las huellas.

¿Travesía de la nada, pasos de nadie? Las bocas de tiempo cuentan el viaje"

(E. Galeano, "Tiempo que dice", Bocas del tiempo)

Huyssen (2007) se ocupa de la denominada "cultura de la memoria" ${ }^{1}$, desplegada globalmente, con fuerza desde los 70 y con intensificación en los 80; si bien los

\footnotetext{
${ }^{1}$ Los ensayos reunidos en el libro de Huyssen fueron escritos en la década de 1990, "en la que se asistió en el mundo entero a una explosión sin precedentes de la cultura de la memoria" (Huyssen, 2007, p. 7). La Capra (2009), a propósito del Holocausto, y revisando algunos conceptos de Freud, menciona "dos conjuntos urgentes de razones para el giro a la memoria y su relación con la historia": a) "la importancia del trauma, incluyendo sobre todo la demora en el reconocimiento de la significación de la serie traumática de acontecimientos de la historia reciente, acontecimientos que preferiríamos olvidar"; b) el interés en los 'lugares de memoria', y a su vez 'no-lugares de memoria', pues "un sitio de la memoria es generalmente también un sitio de trauma y que en la medida en que permanezca investido con las marcas
} 
discursos de la memoria "en el fondo siguen ligados a las historias de naciones y estados específicos" (p. 20):

Uno de los fenómenos culturales y políticos más sorprendentes de los últimos años es el surgimiento de la memoria como una preocupación central de la cultura y de la política de las sociedades occidentales, un giro hacia el pasado que contrasta de manera notable con la tendencia a privilegiar el futuro, tan característica de las primeras décadas de la modernidad del siglo XX. (p. 13)

Aunque se pueda acordar sin dificultad con el autor en que "la globalización y la fuerte revisión de los respectivos pasados nacionales, regionales o locales deben ser pensados de manera conjunta" (y re-tomando acá por nuestra parte algunos aportes de Wallerstein para "abrir las ciencias sociales", pensando en el "sistema-mundo"), no responderíamos con una afirmación tan clara y contundente a la pregunta de "si las culturas de la memoria contemporáneas pueden ser leídas en general como formaciones reactivas a la globalización económica" (p. 21) (y no solo por evitar cierto reduccionismo que parece derivarse de esa apreciación); al menos no siempre es el caso, sino que son "fenómenos" relacionados, que a su vez involucran otros problemas. Son muchas y diversas las estrategias, las finalidades y las implicancias de la memorialización, algunas de las cuales se pueden identificar con solo echar un vistazo alrededor, o tomar algunos sonados casos locales, nacionales e internacionales, que repican en la agenda mediática. Acá y allá se observa y pre-siente el furor de la conmemoración, la musealización y monumentalidad, y los emplazamientos de memoria en espacios públicos, y no siempre o no solo para que "se constituyan en un baluarte que nos defienda del miedo a que las cosas devengan obsoletas y desaparezcan [...] que nos proteja de la profunda angustia que nos genera la velocidad del cambio" (Huyssen, 2007, p. 31). Estos medios y estrategias de memoria (esto es, recuerdo y olvido, selección y exclusión, re-presentación e interpretación, resignificación, re-contextualización, re-organización, re-ensamblajes de todo tipo, palimpsesto, patchwork, pastiche...) también son instrumentos políticos (un tanto "a secas"), económicos, de gestión y administración (pública y privada), "tácticamente polivalentes" (Foucault, 1986), puesto que la memoria es un campo de fuegos cruzados y arma de poder (Le Goff, 1991).

En el despliegue de este "giro memorialista" tienen un rol preponderante la industria cultural, el marketing, el turismo, aunque "Por sí misma la memoria mediática no bastará, por más que los medios ocupen espacios cada vez mayores en la percepción social y política del mundo", para hacer "posibles formas consensuadas de la memoria

del trauma marca hasta qué punto no ha logrado aceptar el trauma, sobre todo a través del duelo" (pp. 2123). Cfr. Ricoeur (2004). 
colectiva" y la "cohesión social y cultural sin esas formas" (Huyssen, 2007, p. 23). Lo que sí se puede observar es el importante trabajo de mass-mediación y su incidencia respecto de la memoria pública, en medio de los múltiples conflictos de políticas de memoria e identitarias (y más si se tiene en cuenta el avance de los medios, y las tecnologías de la información y comunicación en general, y por ejemplo, con relación a la escuela) $)^{2}$.

Basta con prestar un poco de atención a los medios de comunicación e información, en general (aunque sea solo a vuelo de pájaro y en un corte sincrónico, y más aún revisando y analizando el archivo mediático) para a-notar que la constelación semiótico-discursiva 'memoria-historia' es uno de los asuntos importantes que conforman la agenda mediática (McCombs, 2006) y una de las claves de tematización de los medios; y es uno de los recursos retórico-discursivos empleados en la rutina productiva mediática y periodística (léxico, tópico, tropos, entimema y exempla). Así por ejemplo, entre otras operaciones massmediáticas, se pueden observar las siguientes:

- se habla y discute sobre la memoria y la historia, de manera que esto se constituye en lo que está en cuestión como tal;

- la narrativa periodística re-toma el pasado como asunto, lo reactualiza con más información, lo revisa y reinterpreta;

- la construcción de la actualidad emplaza el acontecer en el arco de la temporalidad, da cuenta del presente a partir del pasado, o solo articulándolo con lo pasado, en un re-envío que da (otro) sentido a la realidad actual en cada acto de enunciación y resignifica el pasado a la vez;

- el común e indiscriminado etiquetado periodístico de acontecimientos de toda índole como algo "histórico";

- la proliferación de producciones mediáticas y periodísticas que se ocupan de la memoria y la historia, en diversos géneros, formatos, soportes, que integran los contenidos de secciones y programas o son complementos y suplementos de los medios (i. e., colecciones de todo tipo).

En contrapunto, se da algo así como la re/producción de una "historia anticuaria del presente", que "se identifica plenamente con la sociedad del espectáculo": "La 'ciega furia coleccionadora' de nuestra época entiende la actualidad como una 'exposición universal'", en la que podemos ser actores o espectadores (Virno, 2003, p. 63, citando

\footnotetext{
${ }^{2}$ Algunos núcleos de nuestras propias pre-ocupaciones, desarrolladas en la serie de investigaciones Metamorfosis del contar. Semiosis/Memoria (UNaM) y diferentes trabajos en torno de los medios, los manuales, la historia, la actualidad y la memoria, la identidad (García 2006a, 2006b, 2007, 2008, 2009, 2010b, 2011b, 2011c, 2012).
} 
las "Consideraciones intempestivas" de Nietzsche) $)^{3}$. En esta suerte de promiscuidad de nuestra vida contemporánea, que conjuga diferentes re/cortes temporales (y espaciales), que corta y pega discursos, textos, prácticas y estilos de otrora y ahora, de allá y acá, ajenos y propios, se ponen en tensión de manera más visibles y decibles los mecanismos semióticos de la cultura (Lotman y Uspenskij, 1979, "Sobre el mecanismo semiótico de la cultura"): el recuerdo y el olvido articulan las representaciones e interpretaciones de lo que (nos) pasa, co-operan más o menos armoniosa o conflictivamente en el entramado de signos que conforman la cultura como memoria colectiva (Lotman, 1996), miden sus fuerzas en los tironeos: hacia un cierto "culto al pasado", remembranza, nostalgia y melancolía, recuperaciones y reconstrucciones de un pasado que no fue o no quiere pasar; hacia una instalación presentista, un vivir el instante con más o menos intensidad, dejar/se estar y pasar; hacia un des/encanto del presente, un gradiente de im/paciencia generalizada por la bancarrota de los fondos (en varios sentidos) públicos (y privados), una des/esperanza por el porvenir. Esta des/acomodación dinámica de la estructuración de la temporalidad histórica, que reacentúa con más o menos des/aliento el pasado, el presente y el futuro, y varía sus conjugaciones, está en el ojo de la tormenta del mundo contemporáneo, con/movido por la "explosión" de la memoria. Los medios de comunicación no solo "estructuran y organizan esa presencia del pasado en todos los ámbitos de la vida contemporánea" (Jelin, 2002, p. 9), sino que la operación mass-mediática es cada vez más importante en el trabajo y los días de la memoria (con poco que se vea la reconfiguración de los distintos escenarios locales, regionales, nacionales, mundiales y globales que realiza la sinergia de medios-industrias culturales-turismo y otros "órganos" del complejo sociocultural).

En países como la Argentina (y tantos otros) ${ }^{4}$ es difícil y hasta urticante hablar de memoria: la instancia enunciativa supone y exige una posición discursiva, una

\footnotetext{
3 Vid. la reflexión de Vattimo sobre la "enfermedad histórica" y la "imposibilidad del olvido" (citando a Nietzsche y Heidegger). Señalamos una de las líneas de interés: "en el arte contemporáneo se puede ver en ejercicio una creatividad que no tiene necesidad del olvido, que, por el contrario, se articula exactamente como una función positiva del exceso de memoria" (pp. 83-84). El campo artístico (al igual que el científico y otros) de-muestra el desarrollo y el crecimiento de los signos, que define la memoria (García, 2004, 2011a).

${ }^{4}$ A-notamos el caso de España, que tiene el capítulo del franquismo no revisado plenamente, más allá de la Ley de Memoria Histórica (Babelia, "¿Una memoria antifascista?", 26/04/08: “Derecho. Tras no pocas vicisitudes, el Gobierno del PSOE logró sacar adelante en diciembre pasado la Ley 52/2007, que nunca se llamó de memoria histórica, pero que así ha quedado en nuestra memoria. [...] ley que, aparte de su valor documental, tiene el mérito de suscitar importantes temas para el debate [...]".), y en relación con los "pactos de gobernabilidad", entre otros factores (entre otros problemas que a veces forman parte de la agenda mediática, los juicios a B. Garzón, las manifestaciones públicas del movimiento por "Verdad, Justicia, Reparación", que tienen lugar en distintas ciudades, como lo pudimos volver a comprobar y registrar en nuestro último viaje en 2011; las polémicas por la apertura de fosas comunes y exhumación de restos - p. ej. familiares de García Lorca estaban en desacuerdo con el peritaje que de todos modos fue realizado y demostró que el poeta no había sido enterrado en el lugar identificado hasta entonces-. Aunque la abundante bibliografía conocida a partir del llamado giro de la memoria tiene como uno de sus
} 
propuesta de relación con el otro (destinatarios, predecesores, contemporáneos y sucesores, los otros discursos, el pasado y el presente a partir del cual se considera y evalúa lo pasado, y el futuro deseado), una modalización discursiva (ontológica, epistémica, veridictoria y práctica), una pragmática discursiva (qué fuerzas ilocucionarias y efectos perlocutivos; qué actos performativos y cómo ponderar la dimensión performativa del discurso en general), una ética del discurso (sostener fundada y legítimamente a la vez una pretensión de sentido y la triple pretensión de verdad, rectitud normativa y veracidad). Así, por nuestra parte ponemos en tensión y discutimos los discursos y las prácticas en torno de la memoria en distintos campos y ámbitos que ubican la cuestión en el continuo memoria-historia-dictadura militarjusticia-derechos humanos, que de-limitan un poco los alcances inconmensurables del problema de la memoria (en general) a un pasado más o menos reciente, re-abierto con sus heridas a flor de piel (24 de marzo de 1976 es una fecha investida de gran carga simbólica, que dio lugar a la institución del Día Nacional de la Memoria, por la Verdad y la Justicia); no así la necesidad y legitimidad de las demandas y políticas en curso y aún por implementar al respecto en materia de leyes, "juicios por la verdad y la justicia", "reparaciones"... Una vez re-conocidos los acontecimientos, traumáticos, horribles e imborrables, que se reviven día a día, se recuerdan u olvidan de diferentes maneras, se re-elaboran con diversos medios y finalidades; una vez visto el contexto de activación de los resortes del pensamiento y la acción respecto de la memoria en general y la memoria histórica en las últimas décadas, la gestión de la memoria, los embates y combates que siguen generando esos momentos atroces de nuestro pasado

tópicos el caso de Alemania, también allí hay grietas, cortocircuitos y no pocos debates a medio camino o aún por abrir más ampliamente, y la textualidad más conocida masivamente - - i. e., televisión, como la serie Holocausto de 1979; cine, como Shoah de Lanzmann, de 1985, o La Lista de Schindler de Spielberg; historieta, como Maus de Spiegelman, de 1986 y 1991 - tiene como referencia el término simbólico 'holocausto' y en general el exterminio de los cinco millones de judíos, y si bien parte de la bibliografía y el arte cuenta a los gitanos y homosexuales entre las víctimas del genocidio nazi, no es lo más frecuente ni difundido; recién en 2001 el gobierno alemán rectificó la exclusión de los homosexuales entre las víctimas del exterminio, y se estima que una cuarta parte de los gitanos de Europa fue aniquilada en ese período. $Y$ si se sigue recorriendo el mapa de Europa y América, muchos caminos de la historia son muy espinosos y dolorosos todavía, aunque se derriben muros o estatuas, se cambien de nombres a ciudades, calles o plazas, se abran y revisen algunos archivos, se registren algunos testimonios... Otro caso presente en los medios: a comienzos de abril de 2012, un ciudadano argentino de Córdoba logró el cambio del nombre Videla en su documento de identidad, por la carga de recuerdos y asociaciones...

Las prácticas sociales y los relatos muestran las contradicciones y los conflictos que atraviesan una sociedad, de manera latente o manifiesta, y en casos como estos señalan algunas heridas abiertas y que el trabajo de duelo está en curso o aún queda por hacer. Como dice Bajtin (1985), si el aspecto objetual del pasado no puede ser alterado (por el que comprende), su aspecto expresivo y hablante (de sentido) sí puede ser cambiado. En esta dramatización la memoria juega su rol de "eterna trasformación del pasado". Pero, y por ello mismo, el momento correspondiente, de la respuesta responsable (Bajtin, 1997), el pathos de la participación en la continuidad del devenir del mundo (y) del hombre, esa morada de los signos, demanda la "humildad del sujeto cognoscente; la piedad", la pre-ocupación por los muertos. Vid. Zavala, coord., 1996. 
más o menos reciente, el pensamiento debe volver sobre la "cosa" y sobre sí mismo. Ahí es donde la problemática de la memoria constituye un aspecto relevante de la condición moderna, y por ello uno de los factores importantes de la crisis de modernidad (y) en el mundo contemporáneo.

Schmucler es uno de los pensadores argentinos que reflexiona sobre la memoria y advierte sobre algunas confusiones, ciertos deslizamientos, y la necesidad de tomar recaudos (y diríamos el toro por las astas). En una de sus conferencias (2005) dice:

En nuestro presente asistimos a una curiosa contradicción: tal vez pocos momentos como el nuestro han visto dilatarse en tal magnitud la presencia de la discusión sobre la memoria y, paradójicamente, vivimos una época marcada sustancialmente por el olvido. La memoria misma hace una guiñada al olvido cuando pasa a ser museificada.

Una cristalización que hace menguar la pulsión móvil y perder la capacidad de rehacer la memoria. La memoria, que es la condición de posibilidad de nuestra vida en el mundo, es temible, frágil, imprevisible, esquiva. La memoria es revisión, exige persistencia, voluntad de transmitir, duración y repliegue (para indagarse a sí misma y mantenernos alertas, despiertos). La memoria "es la práctica de una ética": la "idea de una ética constitutiva de la memoria" radica en la selección de lo que se recuerda y se olvida, "que marca el proyecto de existencia de un pueblo". La memoria "es un hecho moral" y "si es considerada como instrumento para algo, si es solamente instrumental, su fuerza moral se debilita" (ídem).

Esto quiere decir que no se puede esquivar las pugnas ideológicas y políticas, los debates públicos y académicos, la responsabilidad y la libertad del mundear, la nada fácil convivencia con otros, la co-pertenencia al mundo y su cuidado, a una comunidad, una ciudad, un país. No podemos negar (sino todo lo contrario, no cejamos en el empeño de propiciar la sensibilización social general, la toma de decisión frente a la historia y la realidad presente, la discusión urgente sobre estos asuntos comunes) la magnitud de los acontecimientos históricos, la importancia de los movimientos sociales, las organizaciones que participan activamente en el proceso de re-solución de estos problemas abiertos y candentes, la pre-ocupación ciudadana en general, las prácticas de intelectuales y académicos que abordan la temática desde distintas perspectivas, las distintas líneas de acción seguidas por varios sectores y gobiernos. Sin embargo, consideramos que una mirada ampliada de la memoria es de más largo alcance y profundidad y re-ubica estos capítulos de nuestra historia de las últimas décadas (Dictadura militar, "desaparecidos", delitos de lesa humanidad, Guerra de Malvinas...) en una narrativa más compleja, poliédrica, polifónica, que permita comprender más y mejor lo que va ocurriendo en relación con "lo que pasó antes que" ( $v$. gr., el ciclo de los golpes militares en Argentina, inaugurado en 1930, en relación con los golpes de estado y gobiernos militares en otros países latinoamericanos; los exterminios de poblaciones indígenas, las varias represiones y masacres...). Queremos 
decir que eso que hace el trabajo académico en Historiografía y ciencias sociales tendría que impregnar más la discursividad pública, oficial y en general. Los alcances y la profundidad de la memoria colectiva, la memoria histórica y la historia no pueden ser re-cortados en períodos de corta duración y de-marcados por algunas fechas más o menos recientes (aunque esto es ciertamente necesario). El problema no es, o no es solamente, preservar y recuperar la memoria, sino ejercitar la facultad de memoria, reelaborar día a día una memoria que pro-sigue sus múltiples cursos y va sedimentando nuestras deriva(ciones) de sentido, prácticas, relatos, re-creaciones...

El desapego moderno al pasado es concomitante con la invención de "una forma de vida inaudita fundada en la anticipación del porvenir. Esto significa que vivimos en un mundo que se 'futuriza' cada vez más" (Sloterdijk, 2011). Pero hoy el "arte de hacer promesas" pierde crédito porque no se pueden saldar tantas deudas acumuladas (ídem). Con las ruinas del "creditismo" la catástrofe se agrava porque no todos ni siempre "lo tomamos en serio" (Zizek, 2011). Una moraleja es que la crisis "es la única instancia que posee suficiente autoridad como para impulsarnos a cambiar nuestra vida" (Sloterdijk). Precisamente vivimos en un mundo de crisis que nos crispa los nervios (de la memoria), por las des/articulaciones y los desen/frenos de todo tipo que experimentamos en todos los órdenes de la vida, echando mano de algunos trechos y pertrechos de las andanzas de Mnemosyne, mirando por momentos hacia atrás y hacia delante para re-acomodar(nos) (en) el presente ${ }^{5}$. A propósito de la facultad de memoria y la génesis del tiempo histórico, Virno (2003) considera que:

El exceso de memoria, que sin duda caracteriza a la situación contemporánea, tiene un nombre propio: recuerdo del presente. [...] cuya peculiar función es representar lo posible, se revela sin recato porque la experiencia de lo posible ha venido asumiendo una importancia crucial en el cumplimiento de las tareas vitales. [...] El excedente de memoria no induce a la abulia y a la resignación sino que, por el contrario, garantiza la más intensa actividad. La parálisis de la acción, acompañada con frecuencia de un irónico desencanto, deriva sobre todo de la incapacidad de soportar la experiencia de lo posible. (pp. 55-56)

Las trans-formaciones de la experiencia, el sentido y los cambios (más o menos in/controlables) de la realidad, la imaginación y construcción de un mundo posible (siempre incierto) se re/producen incesantemente por los juegos complejos de semiosis y memoria (García, 2004, 2011a), que des-encadenan las relaciones constitutivas de la

\footnotetext{
5 Bodei (1998) reflexiona sobre estos dos "rasgos característicos de la modernidad": "La restricción del espacio de la experiencia y una reducción del horizonte de las expectativas". Dice: "La orientación hacia el futuro obedece a dos tendencias simultáneas y contradictorias: es estimulada, ya que la necesidad de prever se acrecienta cuando la incertidumbre aumenta, y a la vez es desmotivada, en razón de la difundida sensación de no estar a la altura de las tareas de simulación y control del porvenir. [...] El horizonte de las expectativas (aunque no el de las esperanzas) se reduce cuando el futuro se muestra más como una amenaza indeterminada que como una promesa plena de contenidos" (pp. 11-12)
} 
urdimbre de sentido(s) en que consiste la vida y la fuerza de la memoria, que a su vez es la vida, la acción y la fuerza de los signos ${ }^{6}$.

Pero la hechura del cuadro epistémico contemporáneo es más rica y embrollada, y los distintos talleres no pueden dar por concluido un trabajo que por definición es permanente, sino que solo pueden trazar algunos bocetos, fragmentos o detalles. En el mismo contexto de los virajes de las últimas décadas se producía también el "giro narrativo", que fue ampliamente reconocido y "tematizado" en el campo de estudios humanos, sociales y culturales (García, 2004, 2010a, 2011a). En el devenir de nuestros trabajos y días (nos) contamos historias una y otra vez. En nuestro trajinar cotidiano accionamos incesantemente la rueca y el telar de narraciones y rememoraciones, para des/tejer y entretejer el sentido, y así vamos bosquejando y trans-formando esa compleja y siempre re-abierta trama de historias que es la cultura (y nuestras propias vidas), explorando caminos interminables que se bifurcan a cada paso, que requieren imaginación y coraje, cuidado y responsabilidad, para hacerse cargo del propio devenir (y) del mundo, la prosecución de la heredad, las tradiciones, las traducciones/traiciones-variaciones de lo que va-siendo ${ }^{7}$.

Precisamente la massmediación es una de las manos tejedoras y partes más visibles y destacadas de ese entramado en el mundo contemporáneo, y no podemos soslayar su papel relevante en ese proceso de continuidad, en el que irrumpe el azar acá y allá, con períodos de relativas in/estabilidades, des/equilibrios, unas que otras catástrofes y disipaciones, a lo largo del cual se re-produce la acción de los signos y en cuyo despliegue consiste el desarrollo, el crecimiento y la creatividad del pensamiento, el conocimiento, el sentido y los propios signos (Peirce). Los periódicos intervienen diariamente en el trabajo de reelaboración de la memoria colectiva, y no es un aspecto menor la dimensión temporal inscripta en la propia denominación ('diario', 'periódico'), máxime si se tienen en cuenta la finalidad del eslabonamiento semiótico continuo y la reformulación de argumentos públicos que realizan los diarios, esto es, la producción de hábitos y creencias (Peirce). De tal manera que la comunicación mediática constituye uno de los cuadros sociales de la memoria colectiva (Halbwachs), en y a partir de los cuales se re-actualiza cotidianamente el presente a partir del pasado y con vistas al futuro (la semiosis continua, incompleta, abierta, se desarrolla hacia y produce sus efectos en el futuro); se re-construyen los significados, se inter-cambia y modela la experiencia (tomando los nudos nocionales de Benjamin, 1989, sobre la narración); se configuran los modos de percibir y valorar la temporalidad y la realidad. En el

\footnotetext{
${ }^{6}$ Hasta aquí, con modificaciones, el apartado correspondiente a "Giro de la memoria" del capítulo "De giros y (sus) re(la)tos. Fragmentos y digresiones" de nuestro libro Comunicación, semiótica, investigación (2011), una versión del cual fue publicado en Razón y palabra 76, México, 2010.

${ }^{7}$ Cfr. por un lado, Bruner $(1996,1997,2003)$, con respecto a la narración y la cultura; y, por otro, Vattimo (1991), sobre la historicidad como pertenencia.
} 
transcurrir vertiginoso del mundo actual y de nuestras vidas, acuciados por la urgencia del presente y la prisa (Marramao, 2011), los diarios escriben, borran, retoman, revisan, corrigen, vuelven a escribir encima, mezclan, reeditan, traspapelan, incansablemente muchas e importantes páginas de varios de los capítulos del "libro de arena" ${ }^{8}$ de la memoria pública. Estos artefactos culturales son usados en y dan lugar a procesos y prácticas sociales que desencadenan significaciones, evocaciones, revocaciones, recuerdos y olvidos, conforme los contextos, los motivos, las finalidades y los intereses de las prácticas. La ritualidad massmediática contribuye a aprender a recordar y permite regenerar, compartir y debatir significados, y es uno de los escenarios privilegiados para actualizar el significado compartido de lo que se hace y se recuerda (como los actos escolares, entre otras tantas formas). Este tipo de re-organización y control institucional del recuerdo y el olvido tiene carácter retórico, crítico y político, en cuanto hace visibles las disputas entre las versiones del pasado estratégicamente construidas, que postulan su candidatura a la validez y el reconocimiento como la elaboración dominante; las polémicas y tensiones de carácter público acerca de, p. ej., la apertura de los archivos, informes y memorias oficiales, al escrutinio público (en Misiones tuvo lugar en marzo-abril de 2012 el cuarto "juicio por la verdad"; recientemente, en 2012, el Gobierno Argentino anunció la publicación del "informe sobre Malvinas"), su revisión y de las versiones del pasado, como parte de las luchas por la imposición de lo que debe ser recordado u olvidado y del significado promovido; y ofrece pistas para reconstruir y analizar aquello que fue objeto de valoración o cuestionamiento, lo que fue "acentuado ideológicamente" (Voloshinov); lo que fue objeto de registro y sanción, y también de manipulación ${ }^{9}$. Todo esto evidencia que la verdad del pasado es construida, sometida a discusión, atacada y defendida día a día a medida que se da cuenta de la actualidad en los medios.

En el mundo contemporáneo la massmediación es central en la gestión de la memoria pública, y para el proceso mnemosemiótico y comunicativo que es la cultura no resultan indiferentes el soporte, los medios y la operación, de modo tal que habría que preguntar "cómo se transmite esto y, al transmitirse, se constituye", con lo cual se apostaría a encontrar alguna punta del porqué. Los vectores de transmisión (como los medios, el escenario, el aula) no operan como meros reproductores de valores, aparte de que no difunden indiferenciadamente cualquier valor o idea; los massmedia, el teatro, la escuela, más que simples instrumentos de difusión, funcionan como

\footnotetext{
${ }^{8}$ Ese libro misterioso que un vendedor de Biblias trata de vender al narrador-personaje del cuento homónimo de J. L. Borges. El "Libro de los libros" "se llamaba el Libro de Arena porque ni el libro ni la arena tienen principio ni fin". Una vez adquirido, el comprador cayó "prisionero del libro" y comprendió que "era monstruoso", para deshacerse de él recordó "haber leído que el mejor lugar para ocultar una hoja es un bosque" y lo perdió en "uno de los húmedos anaqueles" de la Biblioteca Nacional (donde había trabajado), en el sótano donde están los periódicos y los mapas.

${ }^{9}$ Vid. F. Bartlett (1995), sobre el carácter social del recuerdo; y D. Middleton y D. Edwards, comps. (1992), sobre la "memoria compartida" (título del volumen), a partir de aportes como los de Vigotsky.
} 
"ámbitos", y "media", agentes de transformación. La naturaleza y regencia de los soportes y modos de producción renuevan cada vez las prácticas, los tipos y las formas, de las representaciones e interpretaciones (Debray, 1997). Si bien las tecnologías del hacer creer no modifican la necesidad antropológica de creer, así como las del saber no alteran la apetencia de saber, un "navegante" de Internet, un habitante ciberespacial, no experimentará lo mismo y con el mismo valor que un "escriba" en su scriptorium. Las transformaciones de los soportes suponen cambios de los regímenes de creencia y pertenencia; los sistemas de saber y creer se re-constituyen en función de las herramientas disponibles (Debray, 1997, pp. 70-71, 79, 168, 169-72, 179), y cada herramienta (so)porta y actualiza memoria.

Esta operación massmediática interviene en la conformación del archivo -del mundo contemporáneo (esa conjunción de un comienzo y un mandato, "allí donde las cosas comienzan", física, histórica u ontológicamente, y un "principio según la ley", "allí donde se ejerce la autoridad"): esto es, la institución, conservación, continuidad, impugnación y transformación de un orden social (Derrida, 1997). Los medios son algunos de los dispositivos que sostienen el archivo a la vez que permiten y condicionan la archivación y redefinen lo archivado y archivable.

Así volvemos a señalar que el trabajo mediático sobre la actualidad re-activa cada vez los sentidos del pasado en tiempo presente (Cfr. Sarlo, 2005) y tensa el arco hacia el futuro: p. ej., la presencia casi diaria de "Malvinas" desde 2011, y a los 30 años de la guerra en 2012, en la agenda mediática, en portales, sitios o redes de Internet, como Hotmail o Yahoo; un ítem que no mengua la importancia ni desvía la atención mediática y pública de otros ítems de agenda con ribetes de escándalos nacionales, como los casos Schoklender-Fundación Madres y Ciccone-Boudou, atentados a la AMIA y la Embajada de Israel, que re-avivan la memoria colectiva argentina, en relación con la todavía caliente y frágil historia de las instituciones, la dictadura-los derechos humanos-la Fundación Madres, la siempre delicada relación gobierno/medios en el país, la justicia, dado que en los distintos casos se tocan cuerdas muy sensibles de la des/armonía democrática. Los diarios ofrecen versiones del devenir y en ese trabajo de fabulación indican y afirman de alguna manera cierto por-venir. Asimismo, en un posible diálogo parcial entre El mal de archivo de Derrida y La arqueología del saber de Foucault, la massmediación de la memoria pública es parte importante del archivo como "sistema general de la formación y la transformación de los enunciados", por cuanto es una práctica diaria con incidencias considerables en la regulación de lo enunciable (y lo visible), la regimentación de lo que se dice y puede ser dicho, la rearticulación y diferenciación discursiva; la disposición y reelaboración permanente de lo que se recuerda y olvida a partir y a propósito del presente y la actualidad. 


\section{BIBLIOGRAFÍA}

Bajtín, M. (1985). Estética de la creación verbal. México: Siglo XXI.

------ (1997). Hacia una filosofía del acto ético. De los borradores y otros ensayos.

Barcelona: Anthropos.

Bartlett, F. (1995). Recordar. Madrid: Alianza.

Benjamin, W. (1986). "El narrador", Sobre el programa de la filosofía futura y otros ensayos. Barcelona: Planeta-Agostini.

Bodei, R. (1998). Libro de la memoria y de la esperanza. Buenos Aires: Losada.

Bruner, J. (1995). Actos de significado. Madrid: Alianza.

----- (1996). Realidad mental y mundos posibles. Barcelona: Gedisa.

----- (2003). La fábrica de historias. Buenos Aires: FCE.

Certeau de, M. (1978). "La operación histórica", J. Le Goff y P. Nora (dir.) Hacer la historia I. Barcelona: Laia.

Debray, R. (1997). Transmitir. Buenos Aires: Manantial.

Derrida, J. (1997). Mal de archivo. Madrid: Trotta.

Foucault, M. (1985). Historia de la sexualidad I. La voluntad de saber, "Método". México: Siglo XXI.

---- (1996). La arqueología del saber. México: Siglo XXI.

García, M. (1999). La narración de la historia nacional en el texto escolar de Argentina. Tesis doctoral inédita. Universidad Complutense de Madrid.

----- (2002). "Viajar/Contar". Papers ALAIC 2002. Producción científica de Grupos de Trabajo VI Encuentro ALAIC, Santa Cruz de la Sierra, Bolivia: www.eca.usp.br/alaic/gts.htm

---- (2004). Narración. Semiosis/Memoria. Posadas: Editorial Universitaria.

---- (2006a). Comunicación/Educación. Teoría y práctica. Posadas: Editorial Universitaria.

---- (2006b). "Contar (nuestra) Mision(es). Massmediación, memoria, comunidad, identidad", Unirevista, Vol. 1, N. ${ }^{\circ}$ 3. Unisinos, S. Leopoldo, Brasil: www.Unirevista.unisinos.br/.

----- (2007). "Trans-formaciones narrativas y retóricas. Semiosis, memoria, identidad, comunidad, imaginario. Manuales y diarios". Actas (CD) Jornadas Internacionales sobre Retórica y lenguajes de la cultura. Centro Investigaciones Lingüísticas, Fac. de Lenguas Universidad Nacional de Córdoba.

----- (2008). "El in/genio tecno-lógico. Comunicación y memoria". Actas (CD) VI Encuentro Argentino de Carreras de Comunicación Social. Fac. de Ciencias de la Educación, Universidad Nacional de Entre Ríos.

----- (2009). "Con-figuraciones mnemosemióticas. El manual de historia". Acta (CD) III Congreso Internacional Transformaciones culturales: debates de la teoría, la crítica y la lingüística. Fac. de Filosofía y Letras, Universidad de Buenos Aires. 
----- (2010a). "De giros y (sus) re(la)tos. Fragmentos y digresiones". En Razón y palabra. Primera revista electrónica especializada en Comunicación 76, agosto-octubre, México: www.razónypalabra.org.mx

----- (2010b). "Diarios y conflictos. Montaje esceno-gráfico del MERCOSUR". En Diálogos de la Comunicación -Medios y conflictos en Iberoamérica. Más allá de los enfoques políticos $\mathrm{N}^{\circ} 81$, abril-junio. Lima, FELAFACS: http://www.dialogosfelafacs.net/revista/

----- (2011a). Comunicación, semiótica, investigación. Algunas ideas y relaciones. Saarbrücken (Alemania): EAE (España) -LAP Lambert Academic Publishing.

----- (2011b). "Investigación semiótica. Algunas pro-posiciones y relaciones". En Razón y palabra. Primera revista electrónica en América Latina especializada en comunicación 78, noviembre 2011/enero 2012, México: www.razonypalabra.org.mx

----- (2011c). "Massmediación, actualidad y memoria. Archivo, mapas, pistas". C. Andruckievitzs y C. Guadalupe Melo, comps, Cartografías semióticas, E-book VIII Congreso Nacional y III Internacional Asociación Argentina de Semiótica. Asociación Argentina de Semiótica -Programa de Semiótica (UNaM): www.aasemitoca.com.ar

----- (2012). Exploraciones discursivas. E-book, edic. del autor: www.programadesemiotica.edu.ar

García Gutiérrez, A. (2004). Otra memoria es posible. Estrategias descolonizadoras del archivo mundial. Buenos Aires: La Crujía -Junta de Andalucía.

Halbwachs, M. (2004). La memoria colectiva. Zaragoza, Prensa Universitaria de Zaragoza.

Huissen, A. (2007). En busca del futuro perdido. Cultura y memoria en tiempos de globalización. Buenos Aires: Fondo de Cultura Económica.

Jelin, E. (2002). Los trabajos de la memoria. Madrid: Siglo XXI.

La Capra, D. (2009). Historia y memoria después de Auschwitz. Buenos Aires: Prometeo -EDUNTREF.

Le Goff, J. (1991). El orden de la memoria. Barcelona: Paidós.

Lotman, J. (1979). Semiótica de la cultura. Madrid: Cátedra.

----- (1996). La semiosfera (vol. 1). Madrid: Cátedra.

Marramao, G. (2011). La pasión del presente. Barcelona: Gedisa.

Mc Combs, M. (2006). Estableciendo la agenda. Barcelona: Paidós.

Middleton, D. y Edwards, D. comps. (1992). Memoria compartida. Barcelona: Paidós.

Nietsche, F. (1962). "De la utilidad y de los inconvenientes de los estudios históricos para la vida" (1874), Obras completas I. Buenos Aires: Aguilar.

Perice, Ch. S. (1978). Lecciones sobre el pragmatismo. Buenos Aires: Aguilar.

----- (1988). El hombre, un signo. Madrid: Alianza.

----- (2012). Obra filosófica reunida, 2 vols. México: FCE.

Ricoeur, P. (2004). La memoria, la historia, el olvido. Buenos Aires, FCE.

Rossi. P. (2003). El pasado, la memoria, el olvido. Buenos Aires: Nueva Visión. 
Sarlo, B. (2005). Tiempo pasado. Buenos Aires: S. XXI.

Schmucler, H. (2005). "La memoria como ética". Conferencia en la Biblioteca Nacional -ciclo "Pensamiento Contemporáneo": http://laintemperie.com.ar/index/

Uspenski, B. (1993). "La historia y la Semiótica (La percepción del tiempo como problema semiótico)", Discurso -Rvta. Internacional de Semiótica y Teoría literaria- N. ${ }^{\circ}$, pp. 47-89. Sevilla.

Vattimo, G. (1991). Etica de la interpretación. Barcelona: Paidós.

------ (1998). "El olvido imposible", en Y. Yerushalmi, N. Loraux, H. Mommsen, J.-C. Milner y G. Vattimo, Usos del olvido. Buenos Aires: Nueva Visión.

Virno, P. (2003). El recuerdo del presente. Buenos Aires: Paidós.

Voloshinov, V. (1992). El marxismo y la filosofía del lenguaje. Madrid: Alianza.

Wallerstein, I. coord. (1996). Abrir las ciencias sociales. México: Siglo XXI.

Zavala, I., Coord. (1996). Bajtín y sus apócrifos. Barcelona: Anthropos.

Zizek, S. y Sloterdijk, P. (2011). "La quiebra de la civilización occidental" (entrevista por N. Truong). $\tilde{N}$-Clarín (21/08). 